\title{
Kuru Göz Hastalarında Eriyebilen Kanaliküler Tıkaçlar ile Kanalikül Oklüzyonu
}

\author{
Ayşe Dolar Bilge $\odot$
}

Emsey Hospital, Oftalmoloji, Istanbul, Türkiye

Ayşe Dolar Bilge, Dr.
Illetişim:

Dr. Ayşe Dolar Bilge

Emsey Hospital, Oftalmoloji, Istanbul, Türkiye

Tel: +905059213698

E-Posta: draysedolar@gmail.com
Gönderilme Tarihi : 22 Mayıs 2018

Revizyon Tarihi : 11 Eylül 2018

Kabul Tarihi ： 24 Ekim 2018

\section{ÖZET}

Amaç: Kuru göz sebebi ile eriyebilen kanalikül tıkacı uygulanan hastaların klinik özelliklerini ve tedavi sonuçlarını değerlendirmek.

Gereç ve Yöntem: Mart 2014- Aralık 2017 tarihleri arasında, kuru göz sebebi ile eriyebilen kanaliküler tıkaç (Oasys Soft Plug Extended Duration,Glendora, ABD) kullanılarak kanalikül oklüzyonu yapılan 20 hastanın verileri geriye dönük olarak incelendi. Göz kuruluğu Oküler Yüzey Hastalık İndeksi (OSDI) subjektif sorgulama skoru ile değerlendirildi. Eriyebilen tıkaç kanaliküle biyomikroskop altında yerleştirildi.

Bulgular: Otuz yedi gözün 49 kanalikülü (37 alt, 12 üst), eriyebilen kanaliküler tıkaç kullanılarak kapatıldı. Tıkama işleminden sonra kuru göz semptomlarının tekrar başladığı süreler kaydedilerek gereken hastalarda kanaliküler tıkaç yenilendi. Tıkaç yerleştirilmesi sonrasında OSDI skorlarında anlamlı düşüuş izlendi ( $p<0,01)$. Ortalama 8 aylık takip süresi boyunca toplam 83 tıkaç uygulandı, hiçbir hastada tıkaca bağlı komplikasyon izlenmedi.

Sonuç: Eriyebilen kanaliküler tıkaçlar çeşitli nedenlerle ortaya çıkan kuru göz olgularına geçici ve görece düşük maliyetli çözüm sunması sebebi ile oldukça iyi bir alternatif olabilir.

Anahtar sözcükler: Kuru göz; OSDI

\section{CANALICULAR OCCLUSION WITH ABSORBABLE CANALICULAR PLUGS IN PATIENTS WITH DRY EYE}

\section{ABSTRACT}

Objective: To evaluate the clinical characteristics and treatment outcomes of patients who underwent absorbable canalicular plugs with dry eye.

Materials and Methods: The medical records of 20 patients who underwent canalicular obstruction using absorbable canalicular plugs (Oasis Soft Plug Extended Duration, Glendora, USA) between March 2014 and December 2017 were retrospectively reviewed. Dry eye disease was assessed by The Ocular Surface Disease Index (OSDI) subjective questioning score. Absorbable canalicular plugs were inserted using a biomicroscope.

Results: Forty- nine canaliculi (37 lower, 12 upper canaliculi) in 37 eyes were occluded using absorbable canalicular plugs. The resumption of the dry eye symptoms after the canalicular obstruction was recorded and the canalicular plug insertion was repeated when necessary. Significant changes were observed in OSDI scores after canalicular occlusion $(\mathrm{p}<0.01)$. No plug related complication was observed in any patient.

Conclusion: Absorbable canalicular plugs can be a very good alternative as they provide a temporary and relatively low-cost solution to dry eye of various etiologies.

Keywords: Dry eye; OSDI 
K uru göz sendromu \%5-\%35 arasında sıklıkta görülen multifaktöryel bir hastalıktır (1-4). Çeşitli sebeplerle meydana gelen kuru göz hastalığında punktal-kanaliküler tıkama, oldukça etkili bir tedavi seçeneğidir. Bu amaçla en yaygın kullanılan yöntemler, çeşitli materyallerden üretilen punktal ya da kanaliküler tıkaçlar, punktum koterizasyonu, punktumun cerrahi olarak kapatılması gibi yöntemlerdir (5-10). Özellikle ilaç kullanımına bağlı ya da geçirilmiş kornea cerrahisi sonrası dönemde gelişen kuru göz hastalığında, geçici, görece ekonomik ve geri dönüşümlü bir yöntem olması sebebi ile eriyebilen kanaliküler tıkaçlar oldukça kullanışlıdır. Çalışmada eriyebilen kanalikül tıkaçlarının etkinliği ve sonuçlarının tartışılması amaçlanmıştır.

\section{Gereç ve yöntemler}

Çalışma Mart 2014-Aralık 2017 tarihleri arasında Emsey hastanesi Göz Hastalıkları Kliniği'nde eriyebilen kanalikül tıkacı kullanılarak kanaliküler tıkama yapılan 20 olgu ile geriye dönük olarak yapılmıştır. Olguların yaşları 17 ile 88 arasında değişmekte olup, ortalama 44,65 $\pm 21,53$ yıldır. Olguların \%75'i ( $n=15)$ kadın; \%25'i ( $n=5)$ erkektir. Takip süreleri 3 ile 24 ay arasında değişmekte olup ortalaması 8,20 44,56 aydır (Tablo 1). Hastaların demografik özellikleri, kuru göz nedenleri, işlem sonrası klinik bulgular, takip süresi ve komplikasyonlar not edildi. Kuru göz tanısı biyomikroskobik muayene, gözyaşı kırılma zamanı, fluoresein boyanma paterni, Schirmer testine dayanılarak koyuldu. Hastaların işlem öncesi ve sonrası semptomları Oküler Yüzey Hastalık İndeksi (OSDI, Allergan Inc., Irvine, CA, ABD) subjektif sorgulama ile değerlendirildi (11).

OSDI sorgulama, toplam 12 sorudan oluşan bir ankettir ve hastanın son iki haftadır mevcut olan göz kuruluğu semptomlarını sorgular. Hasta, sorgulanan şikayetlerin gün içindeki sıklığına göre;

0: Hiçbir zaman, 1: Bazen, 2: Günün yarısı, 3:Çoğu zaman, 4: Hiçbir zaman şeklinde cevap verir.

OSDI Skoru ise OSDi=[(cevaplanan tüm soruların skorlarının toplamı)x25]/[(cevaplanan soru sayısı) formülü ile hesaplanır. Sonuçlar 0-100 arası bir skalada değerlendirilir. Bu skalaya göre puan arttıkça kuru göz şiddeti de artmaktadır.

İşlemlerin tümü tek göz hekimi tarafından yapıldı (ADB). İşlem öncesi hastalardan aydınlatılmış onam formu alındı.

Kanaliküler tıkama işlemi topikal proparakain (Alcaine, Alcon, ABD) damlatıldıktan sonra biyomikroskop altında, düz penset yardımı ile yapıldı. Kanaliküler tıkacın kanalikül içerisine tam olarak yerleștiğinden emin olunarak işlem sonlandırıldı. Takip süresi boyunca kuru göz semptomları değerlendirildi. OSDI skorlama sorgulaması işlem öncesi ve işlemden iki hafta sonra değerlendirildi. OSDI, skorlamanın 0'dan 100'e kadar bir ölçekte olduğu ve elde edilen skorların hastalığın şiddeti ile doğru orantılı olduğu subjektif bir değerlendirme yöntemidir (11). OSDI skorundaki değişiklikler değerlendirilirken tekrarlanan tıkama işlemi uygulanan hastalarda ilk uygulama öncesi ve sonrası OSDI skorları değerlendirmeye alındı.

İstatistiksel analizler için NCSS (Number Cruncher Statistical System) 2007 (Kaysville, Utah, ABD) programı kullanıldı. Çalışma verileri değerlendirilirken tanımlayıcı istatistiksel metodların (ortalama, standart sapma, medyan, frekans, oran, minimum, maksimum) yanı sıra normal dağııım gösteren nicel verilerin işlem öncesine göre işlem sonrası OSDI skorları değerlendirmesinde Paired Samples test kullanıldı. Anlamlılık $\mathrm{p}<0.05$ düzeyinde değerlendirildi.

\section{Bulgular}

Toplam 20 hastanın, 37 gözünün 49 kanalikülü eriyebilen kanaliküler tıkaç ile kapatıldı. Kanaliküllerin 37'si alt 12 'si üst kanalikül idi. Hastaların 15(\%75)'i kadın, 5(\%25)'i erkek, yaş aralığı 17-88 yıl, ortalama yaş $44,65 \pm 21,53$ idi. Hastaların kuru göz sebepleri isotretinoin (13-cis retinoic acid) kullanımı (6 hasta), flepli kornea cerrahisi (3hasta), katarakt cerrahisi (1 hasta), nörotrofik keratit (1 hasta), tekrarlayan kornea erezyonu sendromu (1 hasta), idiopatik (6 hasta), Sjögren sendromu ( 2 hasta) sebebi ile gelişen kuru göz idi. Kuru göz semptomları düzelip tıkacın erimesi sonrasında tekrar semptomları başlayan 16 hastaya tıkaç işlemi tekrarlanarak uygulandı. Böylece toplamda $83 \mathrm{kez}$ kanaliküler tıkama uygulanmış oldu. Isotretinoin kullanımına bağlı kuru göz gelişen 1 hasta, flepli kornea cerrahisi sonrası kuru göz gelişen iki hasta ve katarakt cerrahisi sonrası kuru göz gelişen 1 hastaya tekrarlayan tıkama işlemi gereksinimi olmadı. İdiopatik kuru göz sebebi ile tekrarlanan eriyebilen tıkaç uygulaması yapılan 3 hastadan 2'sine kalıc silikon punktum tıkacı, 1'ine konjonktival flep tekniği ile punktum oklüzyonu uygulandı(2). Alt ve üst punktumun kapatıldığı hastalarda alt ve üst kapama, epiforaya sebep olabileceği ihtimali ile aynı günde yapılmadı, alt kapamanın yetersiz olduğu hastalarda üst kanaliküler kapama işlemi yapıldı. Hiçbir hastada uygulama sırasında komplikasyonla karşılaşılmadı. Tekrarlayan kapama yapılan hastalarda işlemin tekrarlanma aralığı 3-6 ay idi. OSDI skorları işlem öncesinde ortalama 64,55 $\pm 13,53$ iken, işlem sonrasında $32,01 \pm 10,03$ 'e gerilemiş olup aralarındaki fark 
istatistiksel olarak anlamlı bulunmuştur $(p<0,01)$ (Tablo 2 ve 3). Çalışmamız geriye dönük dosya taraması şeklinde olduğundan etik kurul onayı alınmadı.

Tablo 1. Tanımlayıcı özelliklerin dağlımı
\begin{tabular}{lcc}
$\boldsymbol{n}=\mathbf{2 0}$ \\
\hline Yaş (yıl) & Min-Mak (Medyan) & $17-88(42,5)$ \\
& Ort $\pm S s$ & $44,65 \pm 21,53$ \\
Cinsiyet; $n(\%)$ & Kadın & $15(75,0)$ \\
& Erkek & $5(25,0)$ \\
Takip süresi (ay) & Min-Mak (Medyan) & $3-24(7)$ \\
& Ort $\pm S s$ & $8,20 \pm 4,56$
\end{tabular}

Tablo 2. OSDI ölçümlerinin işlem öncesine göre sonrası değerlendirmesi

\begin{tabular}{lcccc} 
& $\boldsymbol{N}$ & \multicolumn{2}{c}{ OSDI } & $\boldsymbol{P}$ \\
\hline & & Ortalama & SD & \\
İşlem Öncesi & 20 & 64,55 & 13,53 & $0,001^{* *}$ \\
İşlem sonrası & 20 & 32,01 & 10,03 & \\
\hline Paired Samples test ** $p<0,01$ & & &
\end{tabular}

Tablo 3. OSDI skorları dağılım

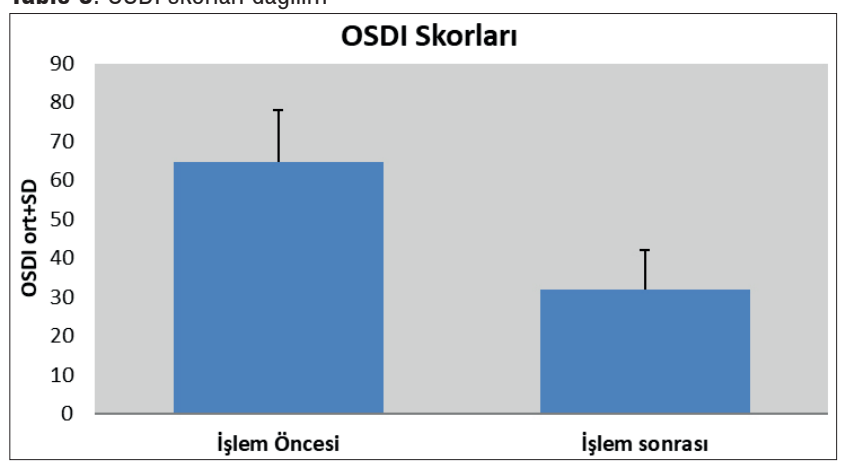

\section{Tartışma}

Çeşitli sebeplerle oluşan göz kuruluğunda medikal tedavi yetersiz geldiğinde ya da medikal tedaviye uyumun iyi olmadığı durumlarda gözyaşı yollarının tıkanması iyi bir alternatiftir. Gözyaşının lakrimal sisteme drenajını bloke ederek gözyaşının göz yüzeyinde daha uzun süre kalması hedeflenir. Bu amaçla ilk kez 1935 yılında Beetham tarafından termal koterizasyon yöntemi ile gözyaşı yolları kapatılmıştır (10). Ancak bu yöntemin dezavantajı geri dönüşümsüz olmasıdır. Hastaların bir kısmında tıkama işlemi sonrasında epifora gelişmesi işlemi başarısız kılmış ve geri dönüşümlü yöntemlerin arayışına sebep olmuştur. 1961 yılında Foulds kalıcı tıkama yöntemi kullanmadan önce epifora gelişip gelişmediğini tayin etmek amacı ile eriyebilen jelatin tıkaçlarını önermiştir (12). Erimeyen punktum tıkaçları ise ilk kez 1975 yılında Freeman tarafından geliştirilmiştir (13). Günümüze kadar bu amaçla punktal ve kanaliküler olarak çok çeşitli tıkaçlar üretilmiştir. Punktum tıkaçları genelikle silikon materyalden üretilir, dizaynları çeşitlilik göstermekle birlikte temel olarak punktumdan kanaliküle kaçması$\mathrm{n}$ engelleyen ve biyomikroskobik muayenede punktum üzerinde görülen bir kapak, ince silindir şeklinde bir gövde ve tam olarak yerleştirildiğinde ampullaya oturan, tıkacın itilip düşmesine engel olan geniş alt kısımdan oluşur $(1,14,17)$. Punktumun üzerini kapatan kapak şeklindeki tepe kısımdan penset ile tutularak çıkartılmaları mümkündür. Punktum tıkaçları geri dönüşüm ve uygulama kolaylığı gibi avantajlarının yanında; yabancı cisim hissi, tıkaç üzerinde biyofilm tabakası oluşumu, kanaliküler sisteme kaçması sonucu kanalikülit ve dakriyosistit oluşumu, pyojenik granülom oluşumu, tıkacın kendiliğinden çıkması ve maliyetinin kanaliküler tıkaçlara görece yüksek olması gibi dezavantajlara da sahiptir $(1,14,15,16)$. Eriyebilen kanaliküler tıkaçlarla ilgili literatürde oldukça az sayıda çalışma mevcut olup bunlar farklı tıkaç dizaynlarının özelliklerini karşılaştıran derleme niteliğinde yazılardır $(1,14,17)$. Eriyebilen kanaliküler tıkaçlar, esasen kalııı yöntemlerin ne kadar etkili olacağını ve işleme toleransı gözlemleyebilmek amacıyla ya da göz kuruluğunun geçici olduğu tahmin edilen durumlarda kullanılır. Jelatin, kollajen, glikolik asit ve trimethylene carbonate, PCL (E-caprolactone L-Lactide copolymer), PDS (polydioxanone) gibi çeşitli materyallerden üretilmişlerdir $(1,12,17,18)$. Tıkaçların erime süresi 1 hafta ile 6 ay arasında değişkenlik göstermektedir. En önemli avantajları oküler yüzey teması olmaması sebebi ile punktum tıkaçlarının en önemli dezavantajlarından biri olan oküler yüzey irritasyonuna sebep olmamaları ve geçici bir süre kanalikülde kalmaları sebebi ile enfeksiyon riskinin daha az olmasıdır (17).

\section{Sonuç}

Çalışmamızda, isotretinoin kullanımına bağlı ve geçirilmiş kornea cerrahisi sonrası kuru göz gelişen hastalarda, kuru göz hastalığının geçici olacağı düşünülerek eriyebilen kanaliküler tıkaçlar tercih edildi. Bu hastaların hiçbirinde kalıcı yöntem gereksinimi olmadı. İdiyopatik kuru göz hastalığı ya da Sjögren sendromu nedeni ile kuru göz gelişen 3 hastada, tekrarlanan eriyebilen kanaliküler tıkaç uygulamaları sonrasında epifora gelişmemesi ve kuru göz semptomlarının iyileşmesi üzerine kalıcı yöntemlere geçildi. Hastaların hiçbirinde kanaliküler tıkaçlara bağlı komplikasyon gelişmedi, kuru göz semptomlarında kötüleşme olmadı. Tüm hastaların kuru göz şikayetlerinde klinik düzelme izlendi.

Eriyebilen kanaliküler tıkaçlar, özellikle geçici kuru göz hastalığına sebep olan durumlarda kolay, geri dönüşümlü, düşük komplikasyon oranına sahip, düşük maliyetli ve oldukça etkili bir tedavi yöntemidir. 


\section{Kaynaklar}

1. Bourkiza R, Lee V. A review of the complications of lacrimal occlusion with punctal and canalicular plugs. Orbit. 2012;31:86-93. [CrossRef]

2. Mc Carty CA, Bansal AK, Livingston PM, Stanislavsky YL, Taylor HR. The epidemiology of dry eye in Melbourne, Australia. Ophthalmology. 1998:105: 1114-9. [CrossRef]

3. Lin PY, Tsai SY, Cheng CY, Liu JH, Chou P, Hsu WM. Prevalence of dry eye among an elderly Chinese population in Taiwan: the Shihpai Eye Study. Ophthalmology. 2003:110: 1096-101. [CrossRef]

4. Messmer EM. The pathophysiology, diagnosis, and treatment of dry eye disease. Dtsch Arztebl Int. 2015:30;112:71-81. [CrossRef]

5. Yazici B, Bilge AD, Naqadan F. Lacrimal Punctal Occlusion With Conjunctival Flap.Ophthal Plast Reconstr Surg. 2015;31:300-2. [CrossRef]

6. Tuberville AW, Frederick WR, Wood TO. Punctal occlusion in tear deficiency syndromes. Ophthalmology 1982;89:1170-2. [CrossRef]

7. Knapp ME, Frueh BR, Nelson CC, Musch DC. A comparison of two methods of punctal occlusion. Am J Ophthalmology 1989;108:3158. [CrossRef]

8. Dohlman $\mathrm{CH}$. Punctal occlusion in keratoconjunctivitis sicca. Ophthalmology 1978;85:1277-81. [CrossRef]

9. Murube J, Murube E. Treatment of dry eye by blocking the lacrimal canaliculi. Surv Ophthalmol. 1996;40:463-80. [CrossRef]
10. Beetham WP. Flamentary keratitis. Trans Am Ophthalmol Soc 1935;33:413-35.

11. Schiffman RM, Christianson MD, Jacobsen G, Hirsch JD, Reis BL. Reliability and validity of the Ocular Surface Disease Index. Arch Ophthalmol. 2000;118:615-21. [CrossRef]

12. Foulds WS: Intra-canalicular gelatin implants in the treatment of keratoconjunctivitis sicca. Br J Ophthalmol 1961;45:625-7. [CrossRef]

13. Freeman JM: The punctum plug:evaluation of a new treatment for the dry eye. Trans Sect Ophthalmol Am Acad Ophthalmol Otolaryngol 1975;79:874-9.

14. Jehangir N, Bever G, Mahmood SM, Moshirfar M. Comprehensive Review of the Literature on Existing Punctal Plugs for the Management of Dry Eye Disease. J Ophthalmol. 2016;2016:9312340. [CrossRef]

15. Rumelt S, Remulla $H$, Rubin PA. Silicone punctal plug migration resulting in dacryocystitis and canaliculitis. Cornea, 1997;16:377-9. [CrossRef]

16. Sugita J, Yokoi N, Fullwood NJ. The detection of bacteria and bacterial biofilms in punctal plug holes. Cornea, 2001;20;362-5. [CrossRef]

17. Taban M, Chen B, Perry JD. Update on punctal plugs. Compr Ophthalmol Update. 2006;7:205-12; 213-4.

18. Herrick RS: A subjective approach to the treatment of dry eye syndrome. Adv Exp Med Biol 1994; 350:571-6. [CrossRef] 